\title{
chaJOPEN
}

\section{Outpatient uterine assessment and treatment unit in patients with abnormal uterine bleeding: an economic modelling study}

\author{
Alexandria Bennett MSc, Kednapa Thavorn PhD, Kristina Arendas MD, Doug Coyle PhD, \\ Sukhbir S. Singh MD
}

Abstract

Background: Most often in Canada, the evaluation and management of abnormal uterine bleeding occurs under general anesthesia in the operating room. We aimed to assess the potential cost-effectiveness of an outpatient uterine assessment and treatment unit (UATU) compared with the current standard of care when diagnosing and treating abnormal uterine bleeding in women.

Methods: We performed a cost-effectiveness analysis and developed a probabilistic decision tree model to simulate the total costs and outcomes of women receiving outpatient UATU or usual care over a 1-year time horizon (Apr. 1, 2014, to Mar. 31, 2017) at a tertiary care hospital in Ontario, Canada. Probabilities, resource use and time to diagnosis and treatment were obtained from a retrospective chart review of 200 randomly selected women who presented with abnormal uterine bleeding. Results were expressed as overall cost and time savings per patient. Costs are reported in 2018 Canadian dollars.

Results: Compared with usual care, care in the UATU was associated with a decrease in overall cost $(\$ 1332,95 \%$ confidence interval $[\mathrm{Cl}]-\$ 1742$ to $-\$ 1008)$ and a decrease in overall time to treatment $(-75,95 \% \mathrm{Cl}-89$ to -63 , d). The point at which the UATU would no longer be cost saving is if the additional cost to operate and maintain the UATU is greater than $\$ 1600$ per patient.

Interpretation: From the perspective of Canada's health care system, an outpatient UATU is more cost effective than usual care and saves time. Future studies should focus on the relative efficacy of a UATU and the total budget required to operate and maintain a UATU.

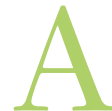

bnormal uterine bleeding is a common condition that presents a substantial burden on patients, society and the health care system. ${ }^{1}$ Conditions that lead to abnormal uterine bleeding, including fibroids, polyps and malignancy, are most often evaluated through a lengthy process of consultations, ultrasonography procedures, return visits, biopsies and surgeries. ${ }^{2-5}$ Hysteroscopy is considered the gold standard for detecting intrauterine pathologies in women with abnormal uterine bleeding; however, hysteroscopy continues to occur under general anesthesia. ${ }^{6-8}$ With current technology, hysteroscopy is both a diagnostic and therapeutic procedure used to manage abnormal uterine bleeding safely in an outpatient setting without general anesthesia. ${ }^{9}, 10$ There is ample evidence showing that hysteroscopy can be performed in an outpatient setting with a high degree of safety and patient satisfaction. ${ }^{11-17}$ In addition, outpatient hysteroscopy improves access to gynecologic care for women by providing timely assessment and treatment while improving the efficiency of care by reducing wait times, improving patient experience and lowering costs to the health care system..$^{4,18-20}$ Unfortunately, most of the data supporting outpatient uterine assessment are based on systems outside of Canada.
Despite the clear advantages of outpatient hysteroscopy, there has been poor adoption of best practice guidance for outpatient uterine assessment and treatment in Canada. ${ }^{21,22}$ As a result, most hysteroscopy cases continue to occur in major operating rooms where the patient is admitted for a surgical procedure. ${ }^{4,23}$ In these cases, the use of general or regional anesthesia presents substantially more risks to the patient and have been shown to be more costly to health care systems compared with procedures outside of the operating room. ${ }^{24,25}$

Competing interests: Sukhbir Singh has been an advisory board member and clinical trial investigator for, and has been provided honoraria for speaking at continuing medical education events by, Hologic Canada, Bayer Pharmaceuticals, AbbVie and Allergan. He has received research support in kind from CooperSurgical. He has been an advisory board member for Merck and Myovant. Kristina Arendas reports grants and personal fees from Allergan and AbbVie, and grants from Bayer, outside the submitted work. No other competing interests were declared.

This article has been peer reviewed.

Correspondence to: Kednapa Thavorn, kthavorn@ohri.ca

CMAJ Open 2020. DOI:10.9778/cmajo.20190170 
Outpatient hysteroscopy is not the primary line of treatment in many health care facilities, and its uptake into clinical practice has been limited because of a lack of training for providers, the need for outpatient clinic space and a lack of relevant Canadian studies showing its cost-effectiveness. ${ }^{26,27}$ Therefore, the aim of this economic study was to evaluate whether it is cost effective to diagnose and treat abnormal uterine bleeding in a single-visit outpatient uterine assessment and treatment unit (UATU) compared with usual care from the perspective of the Canadian health care system.

\section{Methods}

\section{Study design}

We conducted a cost-effectiveness analysis to inform the decision of whether there is a valid argument to fund a UATU compared with usual care. The analysis is from the perspective of the Canadian health care system over a 1-year time horizon and adheres to a recent Canadian guideline for economic evaluation. ${ }^{28}$ Discounting was not necessary since costs and outcomes did not occur beyond 1 year. Probabilities, cost and outcome measures were derived from a retrospective chart review and a systematic review of the existing literature..$^{29}$

\section{Population and setting}

We identified 5283 patients who received gynecologic care at The Ottawa Hospital's Shirley E. Greenberg Women's Health Centre between Apr. 1, 2014, and Mar. 31, 2017, for a retrospective chart review. An independent reviewer (A.B.) screened each identified patient in a randomly generated patient list until 200 patients who were seen for abnormal uterine bleeding, including heavy menstrual bleeding, irregular menses or postmenopausal bleeding, were included. With the help of a second reviewer (S.S.S.), each patient's chart was verified for an abnormal uterine bleeding visit. A sample size of 200 was considered appropriate as clinical experts (S.S.S. and K.A.) thought this would capture an accurate representation of patients being seen for abnormal uterine bleeding at The Ottawa Hospital. Patients were excluded if they were being assessed for infertility or had an abortion or if they had endometriosis because these were elective procedures not targeting pathology.

Information on age, date of first clinic visit, type of uterine evaluation (e.g., ultrasonography, saline infusion sonohysterography, hysteroscopy), type of surgery, type of diagnosis and date of final diagnosis and treatment were extracted by a single reviewer (A.B.) into a Microsoft Excel data abstraction sheet. With the help of a second reviewer (S.S.S.), each patient's chart was verified for an abnormal uterine bleeding visit.

\section{Model structure}

We constructed a decision tree model to estimate costs, probabilities, time to diagnosis and time to treatment associated with a visit to a UATU and usual care for women who present with abnormal uterine bleeding (Figure 1). Usual care refers to the care provided at The Ottawa Hospital by benign (i.e., non-oncology) gynecologists who have completed a residency in obstetrics and gynecology. The care represents general gynecology practice guided by the Society of Obstetricians and Gynaecologists of Canada guideline. ${ }^{22}$

In the usual care branch of our model, management includes the patient's initial consultation followed by further assessments (tests, imaging, repeat visits and surgery, if indicated) until diagnosis and treatment has been reached based on the experiences of the 200 women included in the chart review.

In the UATU branch of our model, all women identified with abnormal uterine bleeding will have access to this unit in parallel with usual care. The main difference of a UATU versus standard of care currently provided is the ability to consult (history, examination), diagnose and treat (certain pathologies) all in 1 visit. Treatment of abnormal uterine bleeding in the UATU includes surgical procedures with the use of a hysteroscope such as polypectomy, endometrial ablation and myomectomy, which can be performed at the visit based on the findings from consultation. In our model, ineligible or failed procedures in the UATU are considered a failed hysteroscopy (unable to evaluate the uterine cavity) and, hence, a failed treatment opportunity in which patients are then directed to further assessment (i.e., additional testing, imaging or hysteroscopy in the operating room).

Cost and time data were assigned to each branch and were multiplied by the respective probabilities to calculate the expected outcomes for both the UATU and the standard of care.

\section{Costs}

This study considered costs borne to the publicly funded health care system in Canada. Hospital cost data were obtained from the Ontario Case Costing Initiative database. Direct hospital costs included costs related to the provision of care, such as the cost of nursing, surgical equipment (including disposables), diagnostic imaging, pharmacy, laboratory services and food services. Indirect hospital costs included overhead expenses relating to hospital operations, such as administration, finances, human resources and plant operations. Cost data for physician services were obtained from the Ontario Schedule of Benefits Physician Services and physician fees listed are amounts payable by the Government of Ontario. ${ }^{30}$ Physician services include provision of the premises, equipment, supplies and personnel used in the performance of the service. For patients who received medication as their primary treatment, drug costs were considered out-of-pocket and not costs borne to the government. Costs associated with the UATU include both direct and indirect costs and take into account the cost for surgeons, assistants and overhead expenses. The costs and codes relating to surgical and physician fees were verified by a clinical expert in the field of gynecology (S.S.S.). The costs are adjusted to 2018 Canadian dollars using a consumer price index reported by Statistics Canada. ${ }^{31}$

\section{Outcomes}

The primary clinical outcome of interest is time to diagnosis. Time to diagnosis was measured as the total time in days 


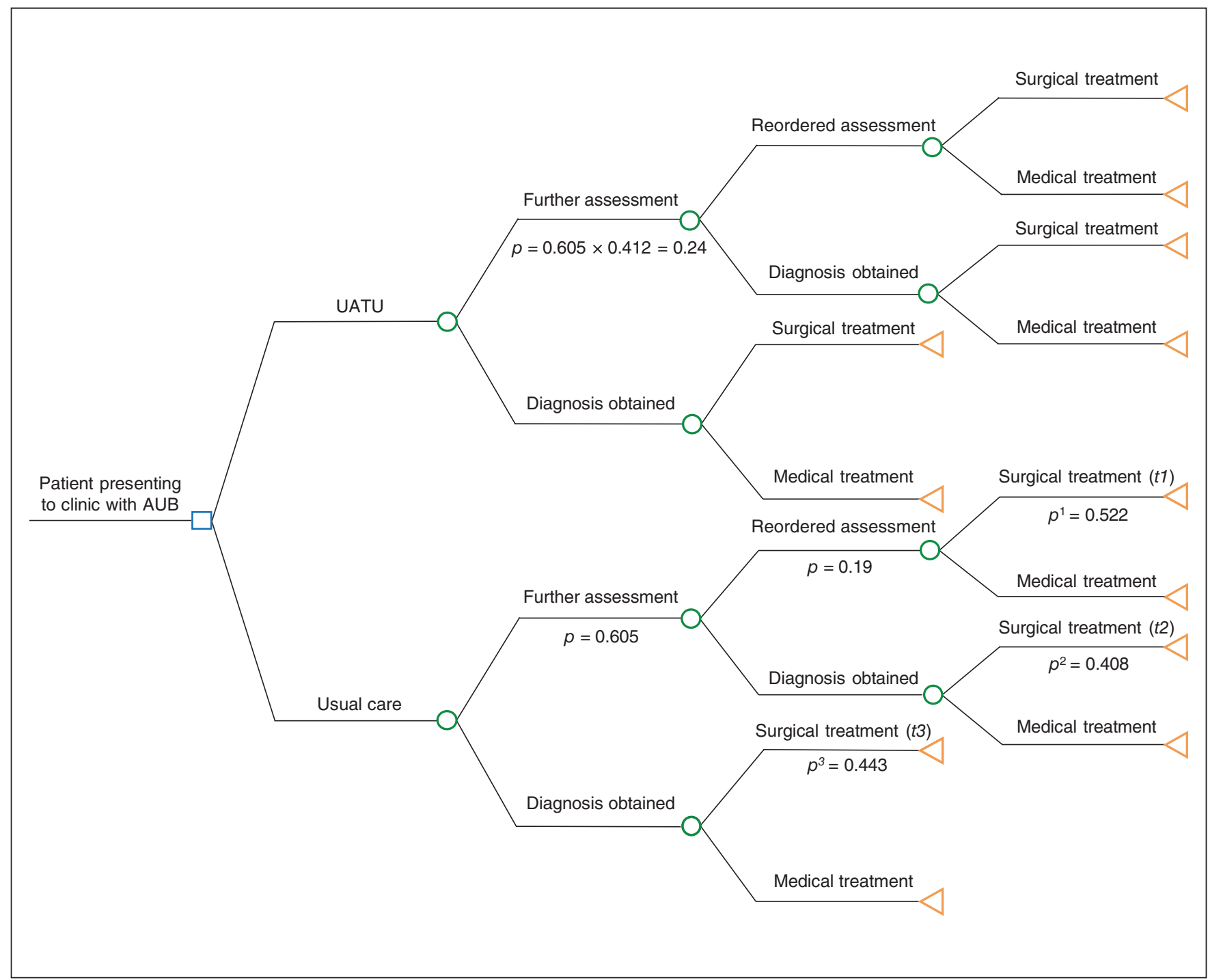

Figure 1: Decision tree model in which $p$ represents the respective probability and $t$ represents the respective time, presented in days. Note: AUB = abnormal uterine bleeding, UATU = uterine assessment and treatment unit.

from initial consult to the date of final consult, in which a diagnosis and management plan was discussed between the physician and patient. The final diagnoses reported in patient charts for abnormal uterine bleeding were defined by the FIGO PALM-COEIN criteria (International Federation of Gynecology and Obstetrics classification system for abnormal uterine bleeding) for defining pathologies and were verified by a gynecologist (S.S.S.). ${ }^{32}$

Our secondary clinical outcome of interest is time to treatment, measured as the total time in days from the initial consult to the first management attempt of abnormal uterine bleeding, including either medical or surgical interventions. For medical management, we measured the final time as the date of the clinical visit in which the prescription was prescribed or recommended. Although both time to diagnosis and time to treatment were surrogate outcomes, they are important measures and key areas of improvement identified by patients, clinicians and hospitals. ${ }^{33}$

\section{Effectiveness of UATU}

We measured the effectiveness of the UATU as a relative risk (RR) of having a failed outpatient hysteroscopy procedure in the UATU that would require a further uterine assessment compared with usual care. To calculate the RR, we calculated the probability of having a failed outpatient hysteroscopic procedure from a systematic review conducted by Clark and colleagues. ${ }^{34}$ The review synthesized 65 full-text studies, in which 755 of 18126 women experienced a failed outpatient hysteroscopic procedure resulting from technical problems (e.g., cervical stenosis, anatomic factors and structural abnormalities) or patient factors (e.g., pain and intolerance). Using the number of patients receiving usual care who required a further assessment from our retrospective review $(n=121)$ and the number of failed outpatient hysteroscopic procedures from Clark and colleagues $(n=755)$, an RR of having a failed outpatient hysteroscopy procedure in the UATU was estimated to be 0.41 (95\% confidence interval [CI] 0.35 to 0.49 ). 


\section{Assumptions}

In our decision model, we assumed that all patients who were to visit the UATU consented to receiving treatment in the outpatient setting. We did not consider patients who would have refused medical work-up in a UATU as they would likely have the same outcomes as if they had received usual care and would have no effect on the results. In addition, we assumed that all patients requiring treatment under usual care were either acute inpatient or day surgery patients. There is currently an active outpatient hysteroscopy suite in its early stages (focusing mainly on treatment rather than diagnosis and treatment in 1 setting) at The Ottawa Hospital, which would function similarly to a UATU. However, in our usual care model, we assumed the outpatient suite did not exist to simulate hospital sites that do not have a similar suite. We also assumed that the cost to operate and maintain a UATU in a hospital setting was equal to usual care since most of the hysteroscopic equipment used in an outpatient setting is already in use in the main operating room at the hospital and would be reflected in most hospitals that provide gynecology care.

\section{Statistical analysis}

Our base-case analysis is conducted to calculate incremental cost-effectiveness ratios for each of the 2 clinical outcomes (time to diagnosis and time to treatment) using an individual sampling model. ${ }^{35,36} \mathrm{We}$ performed a series of 1-way deterministic sensitivity analyses by varying individual model input parameters including effectiveness of UATU and cost parameters to assess various assumptions and the reliability of our conclusions. A probabilistic sensitivity analysis was performed to evaluate the uncertainties in the cost and outcome data. We used a nonparametric bootstrapping method with 5000 replications and used the results to generate a cost-savings acceptability curve to illustrate the probability at which the additional cost per patient to maintain a UATU will be more expensive than usual care. The distribution around each parameter were presented with standard deviations (SDs) and 95\% CIs, which were derived by sorting the bootstrap means from the lowest to highest. The lower and upper bounds of $95 \%$ CIs are equal to the $2.5 \%$ and $97.5 \%$ percentile, respectively. All analyses were conducted using STATA 12 (StataCorp, Stata Statistical Software) and Microsoft Excel 2007 with Visual Basic for Applications (Microsoft Corporation).

\section{Ethics approval}

The study was approved by The Ottawa Hospital's research ethic's board according to protocol no. 20170665-01H.

\section{Results}

\section{Base-case analysis}

Patient demographic characteristics of the 200 included patients from the retrospective chart review are outlined in Table 1, and variable estimates and probability distributions from our base-case analysis are presented in Table 2. The probabilistic base-case analysis is presented in Table 3 , in which we estimated a mean overall cost to obtain a diagnosis at \$427 (SD \$28) for the UATU and \$534 (SD \$44) for usual care, representing a total cost savings of $-\$ 108$ (95\% CI $-\$ 177$ to $-\$ 49)$. We estimated that mean overall costs for obtaining treatment for abnormal uterine bleeding were \$1093 (SD \$109) for the UATU and \$2425 (SD \$240) for usual care, representing a total cost savings of $-\$ 1332(95 \%$ CI $-\$ 1742$ to $-\$ 1008)$.

For time, we estimated a mean overall time to diagnosis at 24 (SD 3) days for the UATU and 55 (SD 5) days for usual care, a time difference of $-32(95 \%$ CI -39 to -25$)$ days. For time to treatment, the overall mean time was 35 (SD 5) days for the UATU and 109 (SD 8) days for usual care, a time difference of -75 (95\% CI -89 to -63$)$ days.

\section{Probabilistic sensitivity analysis}

The results of the probabilistic sensitivity analysis are presented in Figure 2, indicating that the UATU is both less expensive and time saving compared with usual care. The UATU is believed to dominate usual care, illustrating that the UATU is cost-effective.

The cost-savings acceptability curve is presented in Figure 3 , illustrating the probability at which the additional treatment cost per patient to operate and maintain a UATU will be more expensive than usual care. The horizontal dashed line indicates the additional cost at which the UATU is certain ( $100 \%$ probability) to be more expensive than usual care,

\section{Table 1: Demographic characteristics of 200 women seen for} abnormal uterine bleeding included in the chart review

\begin{tabular}{|c|c|}
\hline Characteristic & No. $(\%)$ of patients* \\
\hline Age, yr, mean $\pm S D$ & $45.3 \pm 12.2$ \\
\hline \multicolumn{2}{|l|}{ Menopausal status } \\
\hline Postmenopausal & $47(23.5)$ \\
\hline \multicolumn{2}{|l|}{ Parity } \\
\hline Parous & $138(69.0)$ \\
\hline Nulliparous & $62(31.0)$ \\
\hline \multicolumn{2}{|l|}{ Indication for clinic visit } \\
\hline Heavy menstrual bleeding & $138(69.0)$ \\
\hline Postmenopausal bleeding & $43(21.5)$ \\
\hline Irregular menstrual bleeding & $19(9.5)$ \\
\hline \multicolumn{2}{|l|}{ Diagnosis $\dagger$} \\
\hline Submucosal fibroids & $71(35.5)$ \\
\hline Normal cavity or ovulatory dysfunction & $60(30.0)$ \\
\hline Endometrial polyps & $46(23.0)$ \\
\hline $\begin{array}{l}\text { Abnormal endometrium (hyperplasia } \\
\text { or cancer) }\end{array}$ & $14(7.0)$ \\
\hline Adenomyosis & $14(7.0)$ \\
\hline \multicolumn{2}{|c|}{$\begin{array}{l}\text { Note: } \mathrm{SD}=\text { standard deviation. } \\
\text { *Unless indicated otherwise. } \\
\text { †Some patients were diagnosed with multiple pathologies (e.g., fibroids and } \\
\text { polyps). }\end{array}$} \\
\hline
\end{tabular}




\begin{tabular}{|c|c|c|c|c|}
\hline Parameters & $\begin{array}{l}\text { Baseline } \\
\text { estimate }\end{array}$ & $\begin{array}{l}\text { Standard } \\
\text { error }\end{array}$ & $\begin{array}{l}\text { Probability } \\
\text { distribution* }\end{array}$ & Data source \\
\hline \multicolumn{5}{|l|}{ Outpatient UATU } \\
\hline RR of a failed outpatient UATU hysteroscopy & 0.412 & 0.09 & Lognormal & $\begin{array}{c}\text { Clark et al. }{ }^{31} \text { and } \\
\text { chart review }\end{array}$ \\
\hline Outpatient hysteroscopy costs, $\$ \dagger$ & 152 & 14 & $\begin{array}{c}\gamma \\
(126.8,1.2)\end{array}$ & $\mathrm{OCCl}$ \\
\hline Physician costs for diagnostic hysteroscopy procedure, $\$ \dagger$ & 105 & & Fixed & Schedule of Benefits \\
\hline Costs of surgical procedure in UATU $\ddagger$ & $\$ 600$ & $\$ 150$ & $\begin{array}{c}\gamma \\
(16.0,37.5)\end{array}$ & Expert opinion \\
\hline \multicolumn{5}{|l|}{ Further uterine assessment } \\
\hline Probability & 0.605 & & $\begin{array}{c}\beta \\
(121.0,79.0)\end{array}$ & Chart review \\
\hline Cost of further uterine assessment, $\$ \dagger$ & 690 & & $\begin{array}{l}\text { Weighted } \\
\text { average }\end{array}$ & $\begin{array}{l}\text { Chart review, OCCI, } \\
\text { Schedule of Benefits }\end{array}$ \\
\hline Diagnosis obtained§ & 78 & 6 & $\begin{array}{c}\gamma \\
(161.0,0.48)\end{array}$ & Chart review \\
\hline \multicolumn{5}{|l|}{ Reordered uterine assessment } \\
\hline Probability of receiving reordered uterine assessment & 0.19 & & $\begin{array}{c}\beta \\
(23.0,98.0)\end{array}$ & Chart review \\
\hline Cost, $\$ \dagger$ & 599 & & $\begin{array}{l}\text { Weighted } \\
\text { average }\end{array}$ & $\begin{array}{l}\text { Chart review, } \mathrm{OCCl} \text {, } \\
\text { Schedule of Benefits }\end{array}$ \\
\hline Time to diagnosis§ & 147 & 19 & $\begin{array}{c}\gamma \\
(59.0,2.0)\end{array}$ & Chart review \\
\hline \multicolumn{5}{|l|}{ Surgical treatment } \\
\hline Probability $\left(p^{1}\right)^{\star}$ & 0.522 & & $\begin{array}{c}\beta \\
(12.0,11.0)\end{array}$ & Chart review \\
\hline Probability $\left(p^{2}\right)^{\star}$ & 0.408 & & $\begin{array}{c}\beta \\
(40.0,58.0)\end{array}$ & Chart review \\
\hline Probability $\left(p^{3}\right)^{\star}$ & 0.443 & & $\begin{array}{c}\beta \\
(35.0,44.0)\end{array}$ & Chart review \\
\hline Hospital costs, $\$ †$ & 3514 & & $\begin{array}{l}\text { Weighted } \\
\text { average }\end{array}$ & Chart review, $\mathrm{OCCl}$ \\
\hline Surgeon, assistant and anesthesiologist costs, \$† & 1038 & & $\begin{array}{l}\text { Weighted } \\
\text { average }\end{array}$ & $\begin{array}{c}\text { Chart review, } \\
\text { Schedule of Benefits }\end{array}$ \\
\hline Time to treatment $\left(t^{1}\right) \S$ & 151 & 30 & $\begin{array}{c}\gamma \\
(25.0,6.0)\end{array}$ & Chart review \\
\hline Time to treatment $\left(t^{2}\right) \S$ & 90 & 15 & $\begin{array}{c}\gamma \\
(38.0,2.0)\end{array}$ & Chart review \\
\hline Time to treatment $\left(t^{3}\right) \S$ & 152 & 17 & $\begin{array}{c}\gamma \\
(77.0,2.0)\end{array}$ & Chart review \\
\hline \multicolumn{5}{|c|}{ 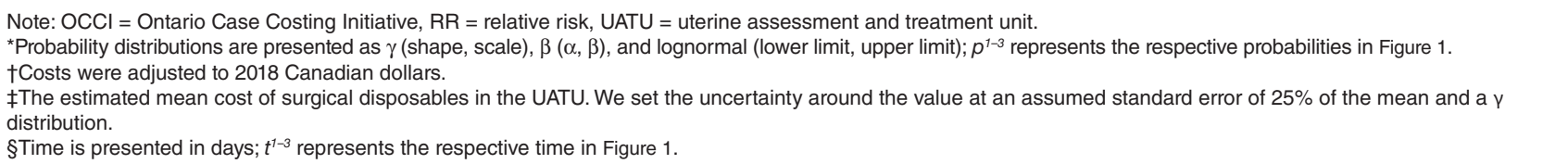 } \\
\hline
\end{tabular}

which is at about $\$ 1600$ per patient. To assess the robustness of our model parameters, we present our sensitivity analysis in Figure 4. The range in values represented by the horizontal bar is greater than 0, illustrating that the UATU service model was consistently less expensive than usual care.

\section{Interpretation}

The results of the cost-effectiveness analysis show that the UATU is less expensive and improves wait times compared with usual care in both diagnosing and treating abnormal 


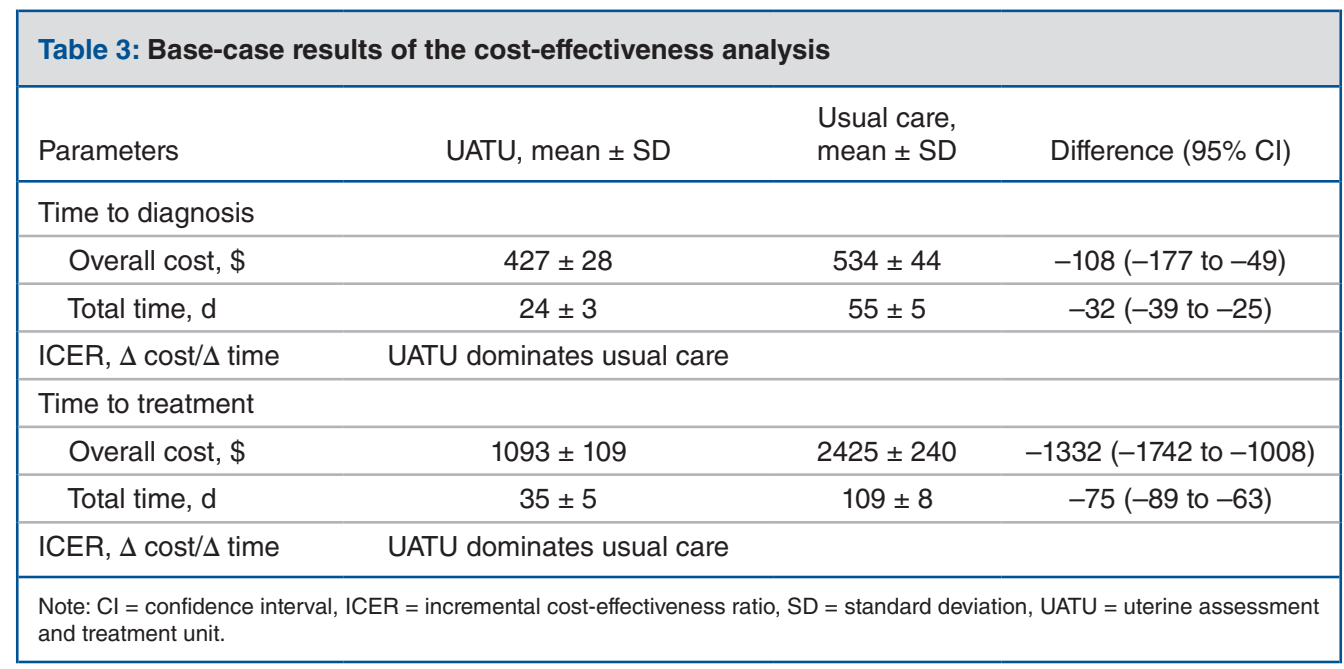

uterine bleeding. The varied estimates in our sensitivity analysis did not change our overall conclusions from the basecase analysis.

Our cost-effectiveness results align with the results of a cost-utility and cost-effectiveness analysis conducted in the United Kingdom that compared outpatient polypectomy with standard inpatient polypectomy in treating patients with abnormal uterine bleeding. ${ }^{37,38}$ The authors concluded that inpatient polypectomy was more expensive and marginally more effective, resulting in the likelihood of effectiveness being roughly equal for both inpatient and outpatient polyp- ectomy at 6 and 12 months. Although the UK study focused on polypectomy and the current study considered any hysteroscopic procedures, the overall conclusions complement each other in that treating patients with abnormal uterine bleeding in an outpatient setting is more cost-effective than providing care in the inpatient setting.

Randomized controlled trials are required to provide the most valid estimates of the relative efficacy of a UATU and usual care. Moreover, a costing study and a budget impact analysis should be conducted to gain further understanding of the total budget required to operate and maintain a UATU.

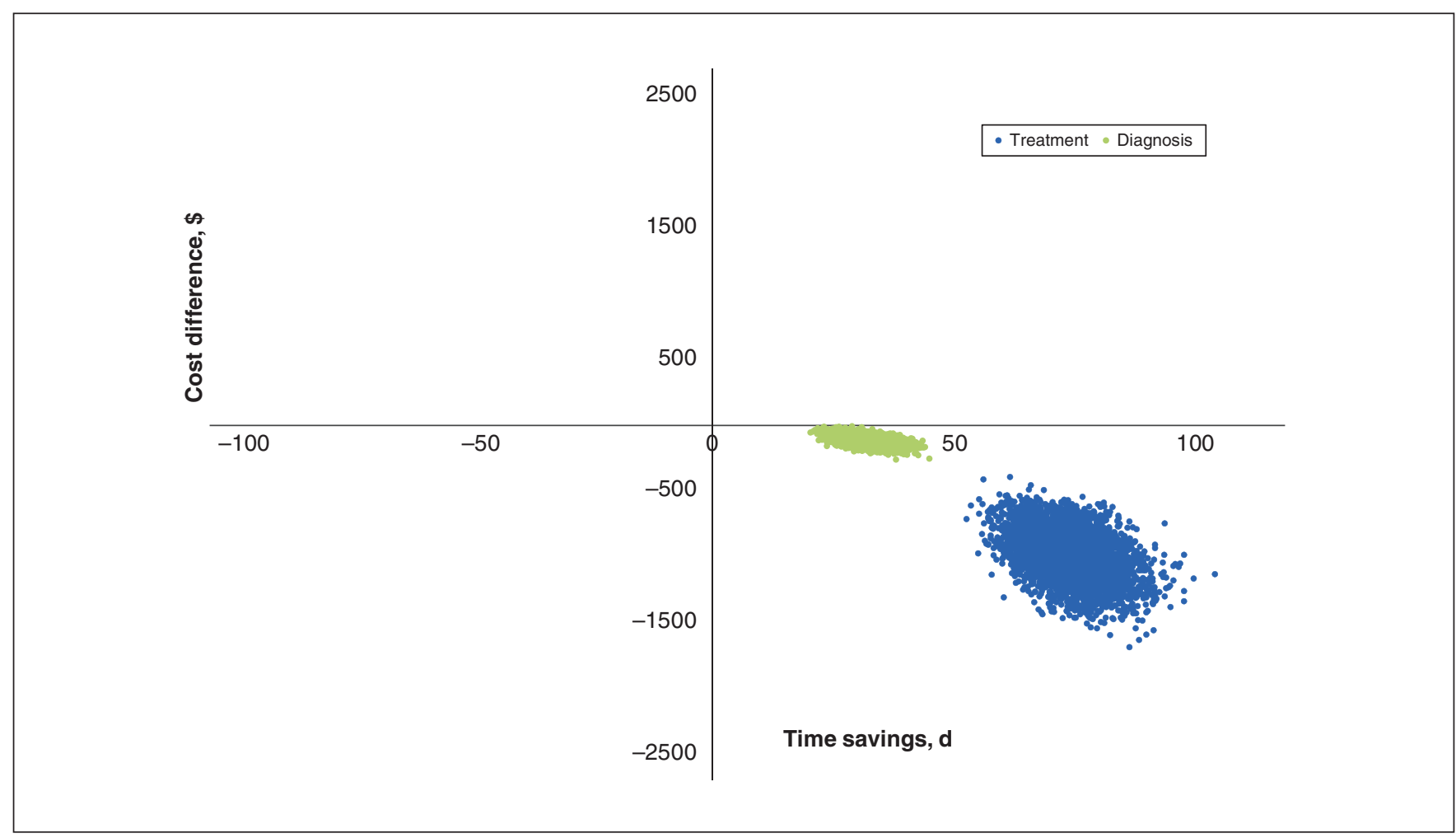

Figure 2: Probabilistic sensitivity analysis for time to diagnosis and time to treatment. 


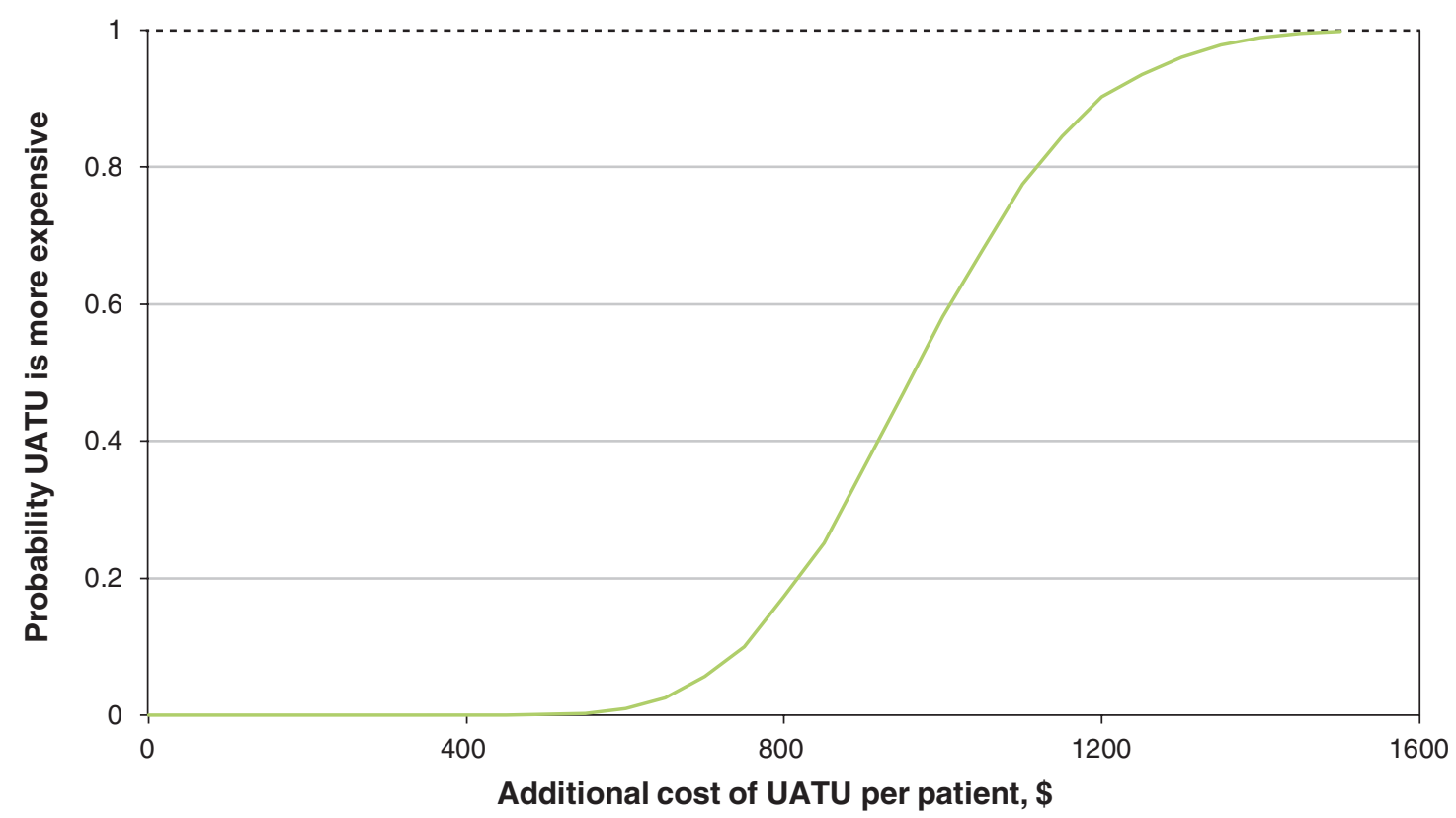

Figure 3: Cost-savings acceptability curve representing the probability at which the additional cost per patient to maintain and operate the UATU will be more expensive than usual care. The dashed line represents the cost at which the UATU will be certainly more expensive (100\% probable) than usual care. Note: UATU = uterine assessment and treatment unit.

Currently, there are no studies or budget impact analyses that assess the total cost of a UATU clinic. In addition, future cost-utility analyses should consider patient satisfaction or quality-of-life metrics associated with a UATU. Given that our study supports timelier diagnosis and treatment, the UATU has the potential to optimize health system performance, which aligns with the Triple Aim framework developed by the Institute for Healthcare Improvement. ${ }^{39}$

\section{Limitations}

Although time is an important clinical outcome to clinicians and patients, it presents some limitations in our economic model. Owing to the paucity of data, the model does not factor in costs, adverse events or other relevant outcomes if a patient were to require further health care resources beyond the set time point of diagnosis or treatment. However, a previous systematic review has shown that the number of adverse events observed in hysteroscopic procedures performed in an outpatient setting was not significantly different from that observed in procedures traditionally performed in an operating room. ${ }^{29}$ Future research is warranted to explore the economic implications beyond the 1-year time horizon of failure to treat abnormal uterine bleeding in a UATU. Similarly, outcomes were expressed as time and not as the recommended quality-adjusted life years. The impact of a UATU on health utility and quality-adjusted life years requires further exploration.
Furthermore, because of the paucity of evidence that directly compared the effects of a UATU to usual care, we used a naive indirect comparison approach by comparing the probabilities of having failed hysteroscopies for a UATU and usual care as if they were obtained from the same study. We were unable to adjust for any potential differences in baseline characteristics of patients included in the systematic review ${ }^{34}$ and our retrospective chart reviews. As a result, the effectiveness of UATU used in this study may be susceptible to bias.

In addition, we did not consider the costs of adopting and maintaining a UATU such as additional costs associated with administration, maintenance or training in a setting where they do not have equipment in their main operating room at present. Since the total cost of the UATU is unknown, we took the assumption that the cost to implement a UATU is equal to usual care. Our rationale was that the additional cost to adopt a UATU will be minimal for many large hospital centres since most hysteroscopic equipment available in the main operating room can be used to set up a UATU. Although this is applicable to large tertiary medical centres, it is important to consider smaller outpatient clinics where an operating room does not exist. To address this limitation, we presented our findings using a cost-savings acceptability curve (Figure 3) to visualize how much more expensive the UATU would have to be per patient to implement and maintain before it was no longer cost saving. 


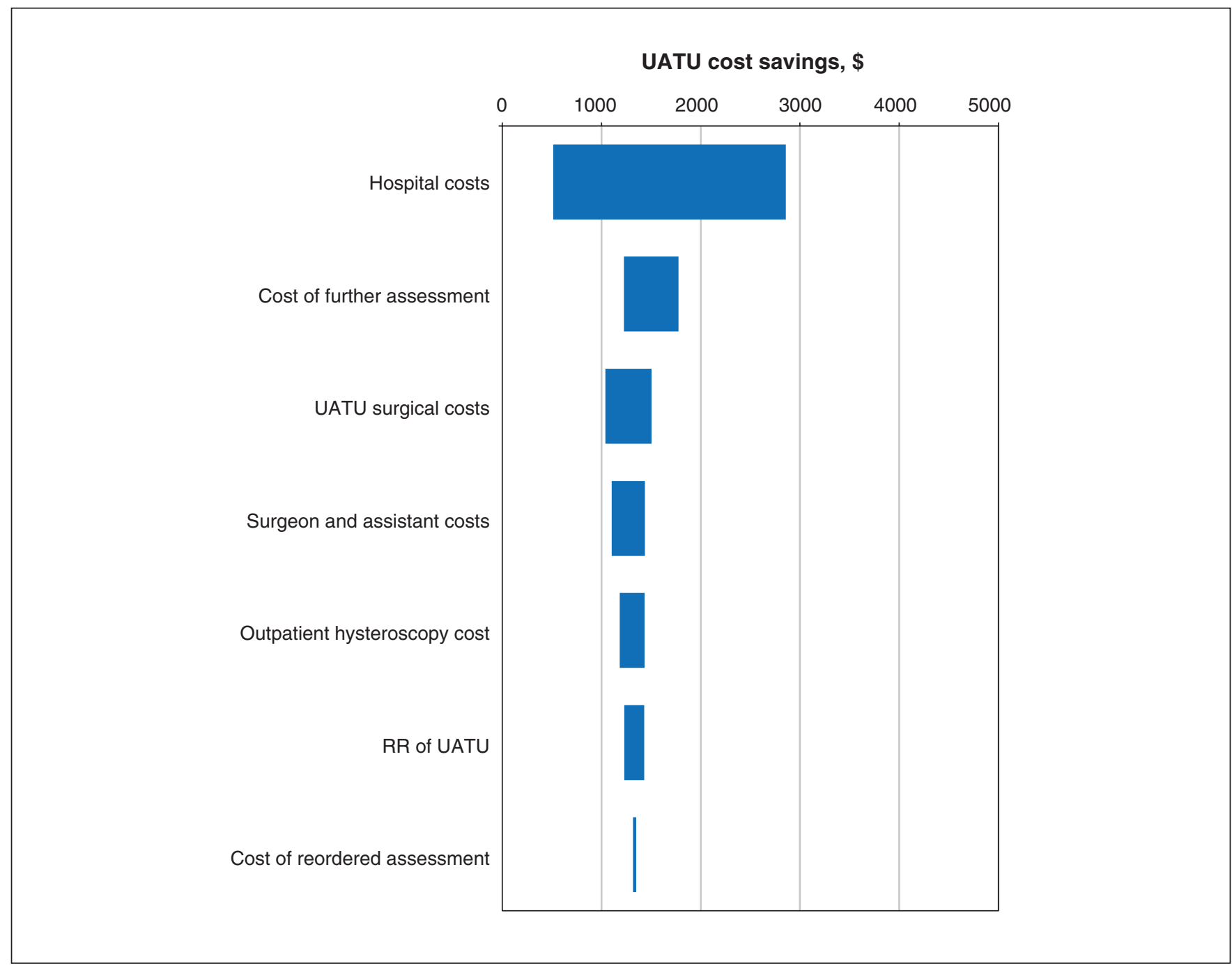

Figure 4: Univariate sensitivity analysis presented as a tornado plot. The range in possible cost savings between the UATU and usual care are presented by varying each input parameter between 2 extreme but plausible values. The input parameter with the widest range in cost savings is presented at the top. Note: $\mathrm{RR}=$ relative risk, UATU = uterine assessment and treatment unit.

The generalizability of our study is also limited. The patient population from which we derived probability, time needed and some cost parameters were from The Ottawa Hospital, a large academic health sciences centre that may have varying clinical practice, experience and techniques in instrument use compared with other institutions to treat and diagnose abnormal uterine bleeding. Health care cost data obtained from the Ontario Case Costing Initiative consider only costs borne to participating hospitals in the Ontario provincial region and may not reflect what occurs outside the province or country; however, our model can be adapted to answer other decision problems in varying jurisdictions. Moreover, our model did not consider the costs from the patient perspective. We did not take into consideration associated costs to the patient such as time off work, medications and transportation while waiting for diagnosis and treatment that would negatively affect the patient's quality of life; however, these patient costs would likely be less with a singlevisit UATU model.

\section{Conclusion}

An outpatient UATU is more cost-effective than usual care in diagnosing and treating abnormal uterine bleeding. The UATU should be considered as the first-line approach as it would improve access to gynecologic care by reducing wait times and lower overall costs to the health care system. The results from this cost-effectiveness analysis provide a tool for objectively assessing the value of implementing an outpatient UATU while allowing clinicians and decision-makers to make rational decisions regarding clinical care and resource allocation.

\section{References}

1. Fraser IS, Langham S, Uhl-Hochgraeber K. Health-related quality of life and economic burden of abnormal uterine bleeding. Expert Rev Obstet Gynecol 2009;4:179-89.

2. Laberge P, Leyland N, Murji A, et al.; Society of Obstetricians and Gynaecologists of Canada. Endometrial ablation in the management of abnormal uterine bleeding. 7 Obstet Gynaecol Can 2015;37:362-79.

3. Munro MG. Practical aspects of the two FIGO systems for management of abnormal uterine bleeding in the reproductive years. Best Pract Res Clin Obstet Gynaecol 2017;40:3-22. 
4. Heavy menstrual bleeding: assessment and management. NICE guideline [NG88]. London (UK): National Institute for Health and Care Excellence; 2018. Available: www.nice.org.uk/guidance/ng88 (accessed 2020 Jan. 20).

5. Singh S, Best C, Dunn S, et al.; Clinical Practice - Gynaecology Committee. Abnormal uterine bleeding in pre-menopausal women. 7 Obstet Gynaecol Can 2013;35:473-5.

6. Grimbizis GF, Tsolakidis D, Mikos T, et al. A prospective comparison of transvaginal ultrasound, saline infusion sonohysterography, and diagnostic hysteroscopy in the evaluation of endometrial pathology. Fertil Steril 2010; 94:2720-5.

7. Nallapati S, Pallavee P, Ghose S. Comparative study of saline infusion sonography and hysteroscopy for evaluation of uterine cavity in abnormal uterine bleeding. Int 7 Reprod Contracept Obstet Gynecol 2015;4:828-32.

8. Zafar H, Naz M, Fatima U. Diagnostic accuracy of saline infusion sonohysterography for evaluation of uterine cavity abnormalities in patients with abnormal uterine bleeding. Prof Med 7 2019;26:892-5.

9. Campo R, Santangelo F, Gordts S, et al. Outpatient hysteroscopy. Facts Views Vis ObGyn 2018;10:115-22.

10. Graham A, Datta S. Outpatient hysteroscopy. Obstetrics, Gynaecol Reprod Med 2016;26:7-11.

11. Ma T, Readman E, Hicks L, et al. Is outpatient hysteroscopy the new gold standard? Results from an 11 year prospective observational study. Aust NZ 7 Obstet Gynaecol 2017;57:74-80.

12. Lee CE, Epp A. Safety and efficiency in a Canadian outpatient gynaecological surgical centre. 7 Obstet Gynaecol Can 2018;40:426-31.

13. Cabezas-Palacios MN, Jiménez-Caraballo A, Tato-Varela S, et al. Safety and patients' satisfaction after hysteroscopic sterilisation. 7 Obstet Gynaecol 2018;38:377-81

14. Capmas P, Pourcelot A-G, Giral E, et al. Office hysteroscopy: a report of 2402 cases. 7 Gynecol Obstet Biol Reprod (Paris) 2016;45:445-50.

15. Rubino RJ, Lukes AS. Twelve-month outcomes for patients undergoing hysteroscopic morcellation of uterine polyps and myomas in an office or ambulatory surgical center. 7 Minim Invasive Gynecol 2015;22:285-90.

16. Wortman M, Daggett A, Ball C. Operative hysteroscopy in an office-based surgical setting: review of patient safety and satisfaction in 414 cases. 7 Minim Invasive Gynecol 2013;20:56-63.

17. Marsh FA, Rogerson LJ, Duffy SRG. A randomised controlled trial comparing outpatient versus daycase endometrial polypectomy. BfOG 2006; 113:896-901.

18. Wortman M. Instituting an office-based surgery program in the gynecologist's office. 7 Minim Invasive Gynecol 2010;17:673-83.

19. Penketh RJA, Bruen EM, White J, et al. Feasibility of resectoscopic operative hysteroscopy in a UK outpatient clinic using local anesthetic and traditional reusable equipment, with patient experiences and comparative cost analysis. $\mathcal{F}$ Minim Invasive Gynecol 2014;21:830-6.

20. Hidlebaugh D. A comparison of clinical outcomes and cost of office versus hospital hysteroscopy. 7 Am Assoc Gynecol Laparosc 1996;4:39-45.

21. Hysteroscopy, best practice in outpatient (Green-top Guideline No. 59). London (UK): Royal College of Obstetricians and Gynaecologists; 2011.

22. Singh S, Best C, Dunn S, et al. No. 292 - Abnormal uterine bleeding in pre-menopausal women. 7 Obstet Gynaecol Can 2018;40:e391-415.

23. Guidelines for the management of abnormal uterine bleeding. 7 Obstet Gynaecol Can 2001;23:704-9.

24. Saridogan E, Tilden D, Sykes D, et al. Cost-analysis comparison of outpatient see-and-treat hysteroscopy service with other hysteroscopy service models. 7 Minim Invasive Gynecol 2010;17:518-25.

25. Levie MD, Chudnoff SG. Office hysteroscopic sterilization compared with laparoscopic sterilization: a critical cost analysis. 7 Minim Invasive Gynecol 2005;12:318-22.

26. Telner DE, Jakubovicz D. Approach to diagnosis and management of abnormal uterine bleeding. Can Fam Physician 2007;53:58-64.

27. Saridogan E, Tilden D, Sykes D, et al. Cost-analysis comparison of outpatient see-and-treat hysteroscopy service with other hysteroscopy service models. 7 Minim Invasive Gynecol 2010;17:518-25.

28. Guidelines for the economic evaluation of health technologies: Canada. 4th ed. Ottawa: Canadian Agency for Drugs and Technologies in Health; 2017.

29. Bennett A, Lepage C, Thavorn K, et al. Effectiveness of outpatient versus operating room hysteroscopy for the diagnosis and treatment of uterine conditions: a systematic review and meta-analysis. 7 Obstet Gynaecol Can 2019;41:930-41.
30. Schedule of benefits: physician services under the Health Insurance Act. Toronto: Ministry of Health and Long Term Care; 2015. Available: www.health.gov.on.ca/en/pro/ programs/ohip/sob/physserv/sob_master11062015.pdf (accessed 2019 Feb. 1).

31. Consumer Price Index (CPI). Ottawa: Statistics Canada; modified 2020 Aug. 18. Available: www23.statcan.gc.ca/imdb/p2SV.pl?Function=getSurvey $\&$ SDDS=2301 (accessed 2019 Mar. 24).

32. Munro MG, Critchley HO, Fraser IS, \& FIGO Menstrual Disorders Working Group. The FIGO classification of causes of abnormal uterine bleeding in the reproductive years. Fertil Steril 2011;95:2204-8.

33. Whitaker L, Critchley HO. Abnormal uterine bleeding. Best Pract Res Clin Obstet Gynaecol 2016;34:54-65.

34. Clark TJ, Voit D, Gupta JK, et al. Accuracy of hysteroscopy in the diagnosis of endometrial cancer and hyperplasia: a systematic quantitative review. 7AMA 2002;288:1610-21.

35. Petrou S, Gray A. Economic evaluation using decision analytical modelling: design, conduct, analysis, and reporting. BM7 2011;342:d1766.

36. Brennan A, Chick SE, Davies R. A taxonomy of model structures for economic evaluation of health technologies. Health Econ 2006;15:1295-310.

37. Diwakar L, Roberts TE, Cooper NAM, et al.; OPT trial collaborative group. An economic evaluation of outpatient versus inpatient polyp treatment for abnormal uterine bleeding. B7OG 2016;123:625-31.

38. Clark TJ, Middleton LJ, Am Cooper N, et al. A randomised controlled trial of Outpatient versus inpatient Polyp Treatment (OPT) for abnormal uterine bleeding. Health Technol Assess 2015;19:1-194.

39. IHI Triple Aim Initiative. Boston (MA): Institute for Healthcare Improvement (IHI). Available: www.ihi.org:80/Engage/Initiatives/TripleAim/Pages/default.aspx (accessed 2019 Apr. 5).

Affiliations: Clinical Epidemiology Program (Bennett, Thavorn), Ottawa Hospital Research Institute; School of Epidemiology and Public Health (Bennett, Thavorn, Arendas, Coyle, Singh), University of Ottawa; ICES uOttawa (Thavorn); Department of Obstetrics, Gynecology, and Newborn Care (Arendas, Singh), The Ottawa Hospital, Ottawa, Ont.

Contributors: Alexandria Bennett contributed to conceptualization, data curation, formal analysis, investigation, methodology, project administration, software, visualization, writing the original draft, revisions and editing. Kednapa Thavorn contributed to conceptualization, data curation, formal analysis, funding acquisition, methodology, project administration, resources, supervision, validation, visualization, writing the original draft, revisions and editing. Kristina Arendas contributed to conceptualization, funding acquisition, supervision and revisions and editing. Doug Coyle contributed to conceptualization, formal analysis, methodology, project administration, supervision, validation, writing the original draft, revisions and editing. Sukhbir Singh contributed to conceptualization, funding acquisition, project administration, resources, supervision, validation, writing the original draft, revisions and editing. All authors gave final approval of the version to be published and agreed to be accountable for all aspects of the work.

Funding: Funding was received from The Ottawa Hospital Academic Medical Organization Innovation Fund.

Data sharing: All data will not be made publicly available. Researchers who require access to the study data can contact the corresponding author for further information (kthavorn@ohri.ca).

Supplemental information: For reviewer comments and the original submission of this manuscript, please see www.cmajopen.ca/content/8/4/ E810/suppl/DC1.

ICES Disclaimer: This study was supported by ICES, which is funded by an annual grant from the Ontario Ministry of Health and Long-Term Care (MOHLTC). The opinions, results and conclusions reported in this article are those of the authors and are independent from the funding sources. No endorsement by ICES or the Ontario MOHLTC is intended or should be inferred. 